\author{
이탈리안 라이그라스 신품종 '그린팜 2호'의 생육특성과 수량성 \\ 지희정 ${ }^{1} *$. 최기준 ${ }^{1} \cdot$ 이상훈 ${ }^{1} \cdot$ 김기용 ${ }^{1} \cdot$ 이기원 ${ }^{1} \cdot$ 박남건 $^{1} \cdot$ 이은섭 ${ }^{2}$ \\ ${ }^{1}$ 국립축산과학원, 천안, 330-801, ${ }^{2}$ 경기도 농업기술원, 화성, 445-784
}

\title{
A Very Early-Maturing Italian Ryegrass (Lolium multiflorum Lam.) New Variety, 'Green farm II'
}

\author{
Hee Chung $\mathrm{Ji}^{1}$, Gi Jun Choi ${ }^{1}$, Sang Hyun Lee ${ }^{1}$, Ki-Yong Kim${ }^{1}$, Ki Won Lee ${ }^{1}$, Nam Gun Park ${ }^{1}$ and Eun Sup Lee ${ }^{2}$ \\ ${ }^{1}$ National Institute of Animal Science, Cheonan, 330-801, Korea, \\ ${ }^{2}$ Gyeonggi-do ARES, Hwasung, 445-784, Korea
}

\begin{abstract}
This experiment was carried out to breed an early maturing variety of Italian ryegrass (Lolium multiflorum Lam.) in the Grassland and Forage Crops Division, National Institute of Animal Science, RDA, Cheonan from 2009 to 2011. A new variety, 'Green farm $\Pi$ ' is a diploid with green leaves and has a semi-erect growth habit in late autumn and erect growth habit in early spring, respectively. 'Green farm $\Pi$ ' was on the $28^{\text {th }}$ of April in the heading date as an early-maturing variety. 'Green farm $\Pi$ ' was also wider by $0.6 \mathrm{~mm}$ in flag leaf width, shorter by $1 \mathrm{~cm}$ in flag leaf length and shorter by $1 \mathrm{~cm}$ in plant length than those of the control variety, 'Florida 80', respectively. 'Green farm $\Pi$ ' was thicker by $0.7 \mathrm{~mm}$ in stem thickness and strong in winter hardness. Dry matter (DM) yield $(11,452 \mathrm{~kg} / \mathrm{ha})$ of 'Green farm $\Pi$ ' was similar to that of 'Florida 80 '. In vitro dry matter digestibility (IVDMD), total digestible nutrients (TDN), and relative feed value (RFV) of 'Green farm $\Pi$ ' were $70.6 \%$, 63.9\%, and $114 \%$ higher than those of 'Florida 80', respectively. Acid detergent fiber (ADF) and neutral detergent fiber (NDF) of 'Green farm II' were $31.7 \%$ and $52.6 \%$ which were $3.5 \%$ and $6.4 \%$ lower than those of 'Florida 80 ', respectively.
\end{abstract}

(Key words : Italian ryegrass, New variety, Green farm II)

\section{I. 서 론}

이탈리안 라이그라스(Lolium multiflorum L.)는 가축 기 호성이 우수하고 사료가치가 높으며 특히 습해에 강하여 우리나라 논에서 벼 수확 후에 겨울철 사료작물로 재배가 적합한 작물이다. 그러나 대부분 농가에 보급되고 있는 이 탈리안 라이그라스 품종들은 숙기가 늦어 우리나라의 중부 지방에서 벼와 이모작으로 재배할 경우 수확 후 이앙기까 지의 작업시간이 충분치 못하고, 또한 도입종 이탈리안 라 이그라스의 뒷그루로 옥수수를 재배할 때에는 앞그루인 이 탈리안 라이그라스의 수확이 늦어서 파종지연에 따른 수확 량 감소가 크기 때문에 농가에서는 이탈리안 라이그라스 재배를 기피하여 왔었다.

현재 우리나라에서 육성된 이탈리안 라이그라스는 총 12 품종으로 4 월 25 일 출수하여 수확기가 가장 빠른 극조생종
인 그린팜( Ji et al., 2011)이 육성되었고, 조생종으로 코그 린(Choi et al., 2006a), 코스피드(Choi et al., 2007), 코윈 어리 (Choi et al., 2011) 등 3품종이 개발되었다. 또한 중생 종으로 코윈마스터가 있고 만생종으로는 화산 101호(Choi et al., 2000), 화산 102호(Choi et al., 2001a), 화산 103호 (Choi et al., 2001b), 화산 104호(Choi et al., 2005), 코위너 (Choi et al., 2006b), 화산 106호가 있다. 그러나 지금까지 국내에서 육성된 이탈리안 라이그라스는 조생종이 4품종 육성되었지만 많은 농가에서는 호밀과 대등한 수확기를 지 닌 품종을 선호하고 있다.

현재 보급중인 이탈리안 라이그라스 조생종 보다 숙기가 빠른 품종으로 국내에선 ‘그린팜'이 최초로 육성된바 있지 만 품종 다양화를 하기 위해서 뿐만 아니라 논 또는 밭에 서 벼와 옥수수의 생산체계를 용이하게 하기 위해서는 숙 기가 빠른 이탈리안 라이그라스 신품종 육성이 필요하기에

* Corresponding author: Hee Chung Ji, National Institute of Animal Science, Cheonan, 330-801, Korea, Tel: +82-041-580-6749, Fax: +82-41-580-6779, E-mail: cornhc@korea.kr 
본 연구를 수행하였다.

\section{II. 재료 및 방법}

본 연구는 이탈리안 라이그라스 극조생 품종 육성을 위해 2001년부터 2011년까지 국립축산과학원에서 수행되 었다.

\section{1. 교배조합 작성}

2001년부터 2011년까지 육성한 극조생종인 내한 27호의 5 개 영양계통은 06CR33, 06CR52, 06CR05, 06CR38, 06CR79 로 합성품종 육성을 위한 교배조합을 작성하였다.

\section{2. 합성계통 종자생산}

다교잡 교배조합의 영양계통은 2007년 Polycross 삼각배 치법으로 합성포장을 조성하고, 주변에는 호밀을 재배하여 외래 화분의 오염을 차단하여 합성계통의 종자를 생산하 였다.

\section{3. 생산력 및 지역적응성 검정}

합성계통의 생산력 검정시험은 2008년 천안에서 실시하 였다. 또한 지역적응성시험은 2009년부터 2011년까지 농촌 진흥청 신품종개발 공동연구사업으로 천안, 연천, 예산, 익 산, 제주 등 5 개 지역에서 3 년간 실시하였으며, 표준품종은 국내에서 도입되고 있는 조생종인 플로리다 80 (Florida 80) 을 표준품종으로 사용하였다. 지역별 파종은 천안과 예산 지역이 9월 하순, 연천이 9월 중-하순, 제주와 익산이 10 월 상순에 파종하였으며, 파종량은 $30 \mathrm{~kg} / \mathrm{ha}$ 으로 하였고, 파 종방법은 $20 \mathrm{~cm}$ 의 세조파로 하였다. 시비량은 $\mathrm{N}_{-}-\mathrm{P}_{2} \mathrm{O}_{5}-\mathrm{K}_{2} \mathrm{O}$ $=200-150-150 \mathrm{~kg} / \mathrm{ha}$, 시비방법은 질소는 기비 $20 \%$, 이른 봄 생육 개시기에 $50 \%, 1$ 차 수확 후 $30 \%$ 로 분시 하였으 며, 인산과 칼리는 기비와 이른 봄 생육 개시기에 각각 $50 \%$ 씩 분시 하였다. 시험구 배치는 난괴법 3 반복으로 실 시하였다. 생육특성은 월동성, 출수기, 도복, 병해, 초장, 풍 엽성 및 재생력 등을 조사하였고, 수량조사는 $6 \mathrm{~m}^{2}$ 시험구 전체를 수확하여 평량 하였다. 품종의 형태적 특성은 천안 에서 조사하였고, 내한성은 지역적응시험지 5 개 지역에서 월동 후 이른 봄에 동사주율과 식생을 달관으로 조사하여 $1 \sim 9$ 로 등급화 하였으며, 이 때 $1=$ 피해 없음, $9=81 \%$ 이 상 동사로 표시 하였다. 수량성은 지역적응시험 5 개 지역
에서 출수기에 시험구 전체를 수확하여 조사하였으며 다만, 예산과 익산에서는 답리작 재배로 1 회만 수확한 성적이다. 시료의 일반성분은 $\mathrm{AOAC}$ 법(1990)으로 분석하였으며, neutral detergent fiber (NDF)와 acid detergent fiber (ADF)는 Goering and Van Soest(1970)법으로 in vitro 건물 소화율 (in vitro digestibility, IVDMD)은 Tilley and Terry (1963)의 방법을 Moore (1970)가 수정한 방법으로 분석하였다. 시험 결과의 통계분석 방법은 SAS 프로그램 $(\mathrm{SAS}, 2004)$ 을 이용 하여 분산분석을 실시하였고, 처리 평균 간의 비교는 Duncan 다중검정법을 이용하였다. 이탈리안 라이그라스 재 배기간 중 내한성에 가장 크게 영향을 미치는 1 월 최저 평 균기온과 강수량은 Table 2와 같으며, 특히 경기 연천지역 에서는 1 월 최저평균기온이 $-11.1 \sim-16.7^{\circ} \mathrm{C}$ 이었고, 강수량 은 0 10 $\mathrm{mm}$ 로 이탈리안 라이그라스가 월동하기에 매우 불량한 환경조건이었다.

\section{III. 결과 및 고찰}

\section{1. 품종특성}

이탈리안 라이그라스 신품종 그린팜 2 호의 주요특성은 Table 1과 같다.

Table 1 과 같이 그린팜 2 호는 2 배체이다. 월동 전 초형 은 반직립형이고, 봄의 초형은 직립형으로서 월동 전 초형 이 반직립형인 플로리다 80 보다 월동에 불리한 초형이다.

Table 1. Comparison of agronomic characteristics between Green farm II and Florida 80

\begin{tabular}{lcc}
\hline \multicolumn{1}{c}{ Characteristics } & Florida 80 & Green farm II \\
\hline \hline Ploidy & Diploid & Diploid \\
Growth habit in autumn & Semi-erect & Semi-erect \\
Growth habit in spring & Semi-erect & Erect \\
Leaf color & Green & Green \\
Flag leaf width (mm) & 7.6 & 8.2 \\
Flag leaf length (cm) & 16.6 & 15.6 \\
Leafiness (1 9)* & 3.0 & 3.0 \\
Plant height (cm) & 95 & 94 \\
Stem thickness (mm) & 2.1 & 2.8 \\
Length of longest stem (cm) & 94.4 & 90.1 \\
Spikelets per ear & 20.0 & 17.0 \\
Length of ear & 23.3 & 21.1 \\
Lodging resistance $(1 \sim 9)^{*}$ & 2.0 & 2.0 \\
Regrowth (1 9)* & 2.0 & 1.0 \\
Heading date & 12 May & 28 April \\
\hline
\end{tabular}

*(1 9) : $1=$ Good (strong), $9=\operatorname{Bad}($ weak) 
그린팜 2호의 지엽 폭과 길이는 각각 $8.2 \mathrm{~mm}, 15.6 \mathrm{~mm}$ 로서 플로리다 80 보다 각각 $0.6 \mathrm{~mm}$ 넓고, $1 \mathrm{~cm}$ 짧으며, 출수기 초장은 $94 \mathrm{~cm}$ 로 플로리다 80 보다 $1 \mathrm{~cm}$ 정도 짧았다. 그린 팜 2호의 줄기 두께는 플로리다 80 보다 $0.7 \mathrm{~mm}$ 굵고, 이 삭 길이는 플로리다 80 보다 $2.2 \mathrm{~cm}$ 짧았다. 그린팜 2 호의 엽색은 플로리다 80 과 비슷한 녹색에 속하였다. 출수기는 4월 28일로, 5월 12일인 플로리다 80 보다 15일 빨라서, 우리나라 중부지역 답리작에서 벼의 이앙에 지장이 없이 수확이 가능한 생육특성을 나타내었다.

\section{2. 내한성}

이탈리안 라이그라스의 월동성에 영향을 미치는 1 월 최 저 평균기온과 강수량은 Table 2와 같다.

Table 2과 같이 경기북부인 연천지역은 2009년부터 2011 년까지 1 월 최저평균기온이 $-11.1 \sim-16.7^{\circ} \mathrm{C}$ 로서 매우 추운 기온을 나타내었다. 특히, 2009년에는 강수량이 전혀 없어 월동에 불리한 기상조건이었으며, 기타 지역은 이탈리안 라이그라스가 월동하는데 큰 문제가 없었다. 이탈리안 라 이그라스 품종의 내한성은 Table 3에서 보는 바와 같이 지 역 및 연차 간에 차이가 없었다. 즉, 천안, 예산, 제주 및 익산지역에서는 그린팜 2호와 플로리다 80 품종 모두 $90 \%$ 이상 월동하여 내한성이 양호한 월동 상태를 나타내었다. 이러한 결과는 이탈리안 라이그라스의 내한성은 유전자원 들의 유전적 특성에 좌우된다는 Pfahler et al.(1984)의 보 고와 같이 내한성이 강한 품종 육성은 우선 추위에 강한 식물체를 선발하고 이를 기본으로 조합된 육종모재의 유전 적 특성에 기인한 것으로 판단되며 특히 내한성 품종 육성 에 있어 내한성을 지닌 유전자원 선발이 더욱 중요한 것으 로 사료되었다.

\section{3. 수량성}

이탈리안 라이그라스의 품종별 건물수량은 Table 4와 같
Table 3. Winter survival degree of Italian ryegrass varieties cultivated in Cheonan, Yunchun, Yesan, Iksan, and Jeju from 2009 to 2011

\begin{tabular}{|c|c|c|c|}
\hline \multirow{2}{*}{ Regions } & \multirow{2}{*}{ Years } & \multicolumn{2}{|c|}{ Winter survival degree (1 9)* } \\
\hline & & Florida 80 & Green farm $\Pi$ \\
\hline \multirow{4}{*}{ Cheonan } & 2009 & 2 & 2 \\
\hline & 2010 & 4 & 1 \\
\hline & 2011 & 1 & 1 \\
\hline & Mean & 2 & 1 \\
\hline \multirow{4}{*}{ Yunchon } & 2009 & 4 & 2 \\
\hline & 2010 & 7 & 7 \\
\hline & 2011 & 5 & 5 \\
\hline & Mean & 5 & 5 \\
\hline \multirow{4}{*}{ Yesan } & 2009 & 2 & 2 \\
\hline & 2010 & 2 & 2 \\
\hline & 2011 & 2 & 2 \\
\hline & Mean & 2 & 2 \\
\hline \multirow{4}{*}{ Iksan } & 2009 & 3 & 3 \\
\hline & 2010 & 1 & 1 \\
\hline & 2011 & 3 & 3 \\
\hline & Mean & 2 & 2 \\
\hline \multirow{4}{*}{ Jeju } & 2009 & 1 & 1 \\
\hline & 2010 & 1 & 1 \\
\hline & 2011 & 1 & 1 \\
\hline & Mean & 1 & 1 \\
\hline Mean & & 2 & 2 \\
\hline
\end{tabular}

* Survival : $1=100 \%, 3=90 \%$ over, $5=89 \sim 60 \%, 7=59 \sim 20 \%$, $9=$ $21 \%$ below.

이 5 개 지역 평균 건물수량은 그린팜 2 호가 $11,452 \mathrm{~kg} / \mathrm{ha}$ 로 서 대비품종인 플로리다 80 의 $12,037 \mathrm{~kg} / \mathrm{ha}$ 과 대등하였다.

지역별로 보면 따뜻한 제주나 예산지역에서는 플로리다 80 이 그린팜 2호 보다 건물수량이 많았는데, 특히 제주지 역에서는 표준품종과 그린팜 2호의 건물수량이 타 지역에 비하여 월등히 많았다. 하지만 겨울철 기온이 급격히 내려 가는 경기북부인 연천지역에서는 그린팜 2 호와 플로리다

Table 2. Weather condition of minimum average air temperature and amount of precipitation in January from 2009 to 2011

\begin{tabular}{|c|c|c|c|c|c|c|c|c|}
\hline \multirow{2}{*}{ Regions } & \multicolumn{4}{|c|}{ Min. average air temp. $\left({ }^{\circ} \mathrm{C}\right)$} & \multicolumn{4}{|c|}{ Amount of precipitation (mm) } \\
\hline & 2009 & 2010 & 2011 & Mean & 2009 & 2010 & 2011 & Mean \\
\hline Cheonan & -2.9 & -3.9 & -6.9 & -4.6 & 13.3 & 40.7 & 7.9 & 20.6 \\
\hline Yunchun & -13.1 & -16.7 & -11.5 & -14.0 & 0.0 & 10.0 & 8.1 & 6.0 \\
\hline Yesan & -7.6 & -8.6 & -6.0 & -7.0 & 12.5 & 55.0 & 9.0 & 26.0 \\
\hline Iksan & -4.8 & -7.8 & -4.9 & -6.0 & 10.0 & 32.0 & 4.5 & 16.0 \\
\hline Jeju & 3.0 & 2.5 & 2.3 & 3.0 & 61.7 & 34.6 & 15.6 & 37.0 \\
\hline
\end{tabular}


Table 4. Dry matter yield of Italian ryegrass varieties cultivated in Cheonan, Yunchon, Yesan, Iksan, and Jeju from 2009 to 2011

\begin{tabular}{|c|c|c|c|}
\hline \multirow{2}{*}{ Regions } & \multirow{2}{*}{ Years } & \multicolumn{2}{|c|}{ Dry matter yield $(\mathrm{kg} / \mathrm{ha})$} \\
\hline & & Florida 80 & Green farm $\square$ \\
\hline \multirow{4}{*}{ Cheonan } & 2009 & 17,900 & 17,618 \\
\hline & 2010 & 11,198 & 12,962 \\
\hline & 2011 & 8,884 & 9,287 \\
\hline & Mean & 12,661 & 13,289 \\
\hline \multirow{4}{*}{ Yunchon } & 2009 & 11,361 & 12,807 \\
\hline & 2010 & 5,087 & 2,749 \\
\hline & 2011 & 10,451 & 10,853 \\
\hline & Mean & 8,966 & 8,803 \\
\hline \multirow{4}{*}{ Yesan } & 2009 & 8,851 & 8,828 \\
\hline & 2010 & 8,543 & 7,734 \\
\hline & 2011 & 7,480 & 5,166 \\
\hline & Mean & 8,291 & 7,243 \\
\hline \multirow{4}{*}{ Iksan } & 2009 & 7,480 & 10,220 \\
\hline & 2010 & 12,700 & 12,050 \\
\hline & 2011 & 10,200 & 9,300 \\
\hline & Mean & 10,127 & 10,523 \\
\hline \multirow{4}{*}{ Jeju } & 2009 & 28,717 & 25,682 \\
\hline & 2010 & 15,469 & 12,066 \\
\hline & 2011 & 16,231 & 14,456 \\
\hline & Mean & 20,139 & 17,401 \\
\hline Mean & & $12,037^{a}$ & $11,452^{a}$ \\
\hline
\end{tabular}

80 가 수량이 다소 적었으나 통계분석 결과 유의한 차이는 없었다. 이상의 결과로 보면, 신품종 그린팜 2호는 겨울이 추운 중북부지역에서 내한성이 비교적 강하며 생산성이 양 호하고 재배 안정성이 높은 극조생 품종으로 사료되었다.

\section{4. 사료가치}

신품종 그린팜 2호의 사료가치는 Table 5와 같다. in vitro 건물소화율 (IVDMD)은 $70.6 \%$ 로서 대조품종 플로리다
80 보다 $1.6 \%$ 높았고, 가소화양분총량 $(\mathrm{TDN})$ 은 $63.9 \%$ 로서 플로리다 80 보다 $2.8 \%$ 높았으며, 산성세제불용섬유 (ADF) 와 중성세제불용섬유 $(\mathrm{NDF})$ 는 31.7 및 $52.6 \%$ 로서 플로리다 80 보다 각각 3.5 및 $6.4 \%$ 낮았다. 특히 상대적 사료가치 (RFV)에서는 114 로 플로리다 80에 비해 월등히 좋은 값을 보였다. 이와 같이 그린팜 2호 품종이 플로리다 80 보다 사료가치가 다소 높은 것은 Table 2에서 보는바와 같이 플 로리다 80 보다 엽폭이 다소 넓은 형태적인 특성으로 사료 된다.

\section{IV. 요 약}

본 시험은 이탈리안 라이그라스 극조생종 품종을 육성하 기 위하여 2001년부터 2011년까지 국립축산과학원 초지사 료과에서 수행되었다. 이탈리안 라이그라스 신품종 그린팜 2 호는 2 배체 작물로 엽은 녹색이며, 월동 전 초형은 반직 립형, 봄의 초형은 직립형이다. 그린팜 2호는 4월 28일경에 출수하는 극조생종 품종이다. 또한, 그린팜 2호는 플로리다 80 보다 지엽폭이 $0.6 \mathrm{~mm}$ 넓고, 지엽의 길이가 $1 \mathrm{~cm}$ 짧으 며, 출수기의 초장은 $94 \mathrm{~cm}$ 로 플로리다 80 보다 $1 \mathrm{~cm}$ 정도 작다. 줄기 두께는 플로리다 80 보다 $0.7 \mathrm{~mm}$ 로 굵고 이삭 길이는 플로리다 80 보다 $2.2 \mathrm{~cm}$ 짧았다. 그린팜 2 호의 건 물수량은 $11,452 \mathrm{~kg} / \mathrm{ha}$ 로서 플로리다 80 과 대등하였다. 그 린팜 2호의 상대적 사료가치는 플로리다 80이 97인데 비해 그린팜 2호는 114로 월등히 높고 in vitro 소화율이 $70.6 \%$, 가소화양분총량 $(\mathrm{TDN})$ 이 $63.9 \%$ 로서 플로리다 80 보다 각 각 $1.6,2.8 \%$ 높았고, 산성세제불용섬유 $(\mathrm{ADF})$ 와 중성세제 불용섬유 $(\mathrm{NDF})$ 는 31.7 및 $52.6 \%$ 로서 플로리다 80 보다 각 각 $3.5 \%$ 및 $6.4 \%$ 낮았다.

\section{$\mathrm{V}$. 인 용 문 헌}

AOAC. 1990. Official methods of analysis (15th ed.) Association \& Official Analytical chemists, Washington DC.

Choi, G.J., Rim, Y.W., Kim, K.Y., Choi, S.H., Sung, B.R., Kim, W.H., Shin, D.E. and Lim, Y.C. 2000. A cold-tolerant and

Table 5. Crude protein (CP), in vitro dry matter digestibility (IVDMD), acid detergent fiber (ADF), neutral detergent fiber (NDF), total digestible nutrient (TDN) and relative feed value (RFV) of Italian ryegrass varieties cultivated in Cheonan from 2009 to 2011

\begin{tabular}{lccccrr}
\hline Varieties & $\begin{array}{c}\text { CP } \\
(\%)\end{array}$ & $\begin{array}{c}\text { IVDMD } \\
(\%)\end{array}$ & $\begin{array}{c}\text { ADF } \\
(\%)\end{array}$ & $\begin{array}{c}\text { NDF } \\
(\%)\end{array}$ & $\begin{array}{c}\text { TDN } \\
(\%)\end{array}$ & RFV \\
\hline \hline Florida 80 & 10.0 & 69.0 & 35.2 & 59.0 & 61.1 & 97 \\
Green farm $\Pi$ & 9.3 & 70.6 & 31.7 & 52.6 & 63.9 & 114 \\
\hline
\end{tabular}


high-yielding Italian ryegrass (Lolium multiflorum L.) new variety 'Hwasan 101'. Journal of the Korean Society of Grassland and Forage Science. 20:1-6.

Choi, G.J., Rim, Y.W., Lim, Y.C., Kim, K.Y., Sung, B.R., Kim, M.J. Park, G.J. and Kim, S.R. 2001a. Growth characters and productivity of new Italian ryegrass (Lolium multiflorum L.) variety 'Hwasan 102'. Journal of the Korean Society of Grassland and Forage Science. 21:157-162.

Choi, G.J., Rim, Y.W., Lim, Y.C., Kim, K.Y., Sung, B.R., Choi, S.H. and Park, G.J. 2001b. Growth characters and productivity of new Italian ryegrass (Lolium multiflorum L.) variety 'Hwasan 103'. Journal of the Korean Society of Grassland and Forage Science. 21:163-168.

Choi, G.J., Rim, Y.W., Sung, B.R., Lim, Y.C., Kim, M.J., Kim, K.Y., Park, G.J., Park, N.K., Hong, Y.K. and Kim, S.R. 2005. Growth characters and productivity of new Italian ryegrass (Lolium multiflorum L.) variety 'Hwasan 104'. Journal of the Korean Society of Grassland and Forage Science. 25:275-280.

Choi, G.J., Lim, Y.C., Rim, Y.W., Sung, B.R., Kim, M.J., Kim, K.Y. and Seo, S. 2006a. A cold-tolerant and early-heading Italian ryegrass (Lolium multiflorum L.) new variety 'Kogreen'. Journal of the Korean Society of Grassland and Forage Science. 26:9-16.

Choi, G.J., Lim, Y.C., Rim, Y.W., Kim, K.Y., Sung, B.R., Rim, Y.W., Kim, M.J., Lim, K.B. and Seo, S. 2006b. A cold-tolerant and high-yielding Italian ryegrass (Lolium multiflorum L.) new variety 'Kowinnner'. Journal of the Korean Society of Grassland and Forage Science. 26:171-176.

Choi, G.J., Lim, Y.C., Sung, B.R., Kim, K.Y., Lee, J.K., Lim, K.B., Park, H.S., Seo, S. and Ji, H.C. 2007. A cold-tolerant and early-maturing Italian ryegrass (Lolium multiflorum L.) new variety 'Kospeed'. Journal of the Korean Society of Grassland and Forage Science. 27:145-150.

Choi, G.J., Ji, H.C., Kim, K.Y., Park, H.S., Seo, S., Lee, K.W. and Lee, S.H. 2011. Growth characteristics and productivity of cold-tolerant 'Kowinearly' Italian ryegrass (Lolium multiflorum L.) in the northern part of South Korea. African Journal of the Biotechnology. 10:2676-2682.

Goring, H.K. and Van Soest, P.J. 1970. Forage fiber analysis. Ag. Handbook. No. 379. ARS. USDA. Washington D.C.

Ji, H.C., Lee, S.H., Yoon, S.H., Kim, K.Y., Choi, G.J., Park, H.S., Park, N.G., Lim, Y.C. and Lee, E.S. 2011. A very earlymaturing Italian ryegrass (Lolium multiflorum Lam.) new variety, 'Green Farm' for double cropping system. Korean Society of Grassland and Forage Science. 31:9-14.

Pfahler, P.L., Barnett, R.D. and Luke, H.H. 1984. Diploid-tetraploid comparisions in rye. I. Forage Production. Crop Science. 24: 67-1674.

SAS. 2004. SAS/STAT 9.1 User's Guide. SAS inst, In, Cary, NC.

Tilley, J.A.M. and Terry, R.A. 1963. A two stage technique for in vitro digestibility of forage crops. Journal of Britannica Grassland Science. 18:104-111.

(Received February 20, 2013/Accepted March 5, 2013) 